\title{
QUALIFICAÇÃO SOCIAL E PROFISSIONAL A PARTIR DA LÓGICA DOS MOVIMENTOS SOCIAIS DO CAMPO
}

\author{
Edna Castro de Oliveira \\ Universidade Federal do Espírito Santo (UFES), Vitória, Espírito Santo, Brasil \\ Maria Geovana Melim FerrelRa \\ Secretaria de Estado da Educação do Espírito Santo (SEDU-ES), Vitória, Espírito \\ Santo, Brasil
}

\begin{abstract}
Resumo: 0 texto aborda resultados de pesquisa de mestrado realizada a partir da implementação do Programa ProJ ovem Campo Saberes da Terra (PJC-ST) no ES, voltado para a escolarização de camponeses com Qualificação Social e Profissional (QSP) na modalidade EJA. Tem como objetivo explicitar os desafios postos aos processos formativos no contexto do campo nas práticas de Educação Profissional. Toma como aportes teóricos a educação popular, os fundamentos e princípios da agroecologia e o trabalho como princípio educativo para o exercício da integração curricular. A metodologia da sistematização é assumida como forma de revisitar a prática e analisá-la criticamente. Os resultados indicam contribuições para o campo da política pública de EJ A, tendo o diálogo de saberes, a alternância pedagógica e as práticas de QSP como elementos integradores do currículo.
\end{abstract}

Palavras-chave: Movimentos Sociais. Qualificação Social e Profissional. Educação de Jovens e Adultos. Educação do Campo.

INTRODUÇÃO

Como uma das ações de política pública voltadas para um dos segmentos da juventude brasileira, o ProJ ovem Campo - Saberes da Terra (PJC-ST), com sua ênfase na qualificação social e profissional de jovens e adultos, teve sua origem nas lutas e proposições dos movimentos sociais do campo e ganhou força e abrangência na busca de se efetivar como uma política de formação para os trabalhadores do campo.

Partimos da compreensão de que as políticas neoliberais, que imperam na conjuntura educacional brasileira, revelam sua posição de classe em favor do capital. Em meio às disputas territoriais do campo capixaba, elas tendem a se reproduzir nas políticas dirigidas às modalidades da Educação do Campo e da Educação Profissional, vinculadas 
diretamente ao Plano Estratégico de Desenvolvimento da Agricultura Capixaba (PEDEAG), que atendem ao projeto capitalista do Agronegócio ${ }^{1}$.

Neste contexto, a proposta do PJC-ST representou um contraponto à referida lógica ao tomar a agroecologia ${ }^{2}$ como base técnica da qualificação profissional, tendo 0 Arco Ocupacional ${ }^{3}$ Produção Rural Familiar como possibilidade de efetivação dessa formação. No Espírito Santo (ES), atuou com 120 educadores nas 29 turmas, distribuídas em 19 municípios. Os desafios postos no percurso envolveram concretamente: a formação e atuação docente por áreas de conhecimento (Ciências Agrárias, Linguagens e Códigos, Ciências Humanas, Ciências da Natureza e Matemática), o desenvolvimento da alternância pedagógica ${ }^{4}$, bem como 0 acompanhamento in loco e as práticas de qualificação social e profissional, na perspectiva da integração dos saberes científicos e populares. Para tal, a pesquisa e o trabalho, como princípios educativos, foram assumidos como essenciais nas relações com o conhecimento produzido.

Ao longo do texto, procuramos evidenciar a centralidade do trabalho no seu duplo sentido, da práxis humana e da práxis produtiva, tal como expressado por Konder (1992, p. 115) ao enfatizar a práxis como "atividade concreta pela qual os sujeitos se afirmam no mundo, modificando a realidade objetiva e, para poderem alterá-la, transformando-se a si mesmos". Também ganha foco a força da educação popular na perspectiva libertadora, como teorização e práxis, com sua valorização dos saberes naquilo que se buscou vivenciar como proposta de um currículo integrado.

No texto, organizado em três partes, tratamos da "profissionalização da classe trabalhadora do campo", onde refletimos acerca da educação profissional a partir dos parâmetros da Educação do Campo, que consideram a realidade do trabalho no campo, os embates dos projetos de desenvolvimento, os modos de fazer agricultura e as experiências de formação profissional dos sujeitos. Em seguida, lançamos mão de algumas análises da sistematização de experiências para refletir sobre "o trabalho como princípio educativo: tecnologia e saberes populares", onde apontamos a alternância pedagógica como ferramenta para a integração no exercício das práticas da QSP na perspectiva agroecológica e como estratégia de formação. Na sequência, sem a pretensão de concluir, mas de provocar novas reflexões, apresentamos uma possibilidade de construção coletiva do currículo integrado a partir do diálogo dos saberes e do trabalho coletivo exercitado entre formadores, educadores e educandos, cuja materialidade tentamos expressar no item "qualificação social e profissional como elementos da integração curricular a partir dos princípios da educação popular" e algumas reflexões sobre "o legado do ProJovem Campo - Saberes da Terra no ES".

\section{A PROFISSIONALIZAÇÃO DA CLASSE TRABALHADORA DO CAMPO}

No âmbito da educação dos camponeses, o trabalho passa a fazer parte desde muito cedo da vida das pessoas, define uma forma diferente de viver e produz relações sociais, culturais e econômicas diferenciadas. Nesse sentido, ao tomarmos o trabalho como princípio educativo, coloca-se a necessidade de se pensar processos educativos diferenciados para a Educação do Campo (MOLINA, 2014). Pressupõe-se que, para a classe 
trabalhadora do campo, interessa uma educação que considere os seus valores e as formas de fazer agricultura, vinculadas às práticas e às lutas camponesas.

De modo geral, não se considera que esse jeito próprio do camponês de fazer agricultura deva ser estudado, nem que ele necessite de uma formação científica e tecnológica para ser praticado, pois se entende que essa lógica de produção e trabalho deva ser eliminada, bastando aos camponeses o saber da experiência (CALDART, 2010) Tocamos aqui uma questão que, a nosso ver, tenciona os movimentos sociais do campo e os mantém em alerta. Isto porque "o modo de produção capitalista que se caracteriza por relações sociais especificas, quais sejam trabalho assalariado livre (compra e venda de força de trabalho) e a existência de meios de produção sob a forma de mercadoria" (BOTTOMORE, 1988, p. 89) disputa, de forma mais acirrada no contexto do campo brasileiro, a formação para a produção demandada pelo mercado, com a lógica de formação da produção camponesa, que busca afirmar seus saberes e a vida na sua integralidade. Essa disputa leva Caldart a afirmar que:

[...] a educação profissional pensada desde a perspectiva política e teórica da Educação do Campo defende, sim, a valorização do saber da experiência camponesa (porque sem ela perdemos a sabedoria e a ciência da produção de alimentos voltada para a reprodução da vida) [enfatizando assim a superação] do conhecimento tácito [e defendendo o diálogo] com a ciência e a tecnologia (CALDART, 2010, p. 237).

Nessa direção, Freire (2011, p. 74) nos adverte sobre o "saber de experiência feito" que, para ele, "tem de ser o ponto de partida em qualquer trabalho de educação popular orientado no sentido da criação de um conhecimento mais rigoroso". Nesse diálogo, Caldart (2010) insiste, como já vimos, na crítica à desconsideração do modo camponês de fazer agricultura, uma vez que tem se naturalizado a ideia de que esse não "deve ser estudado, nem que ele necessite de uma formação científica e tecnológica para ser praticado" (CALDART, 2010, p. 237). Esta postura é reiterada por Freire (2011, p. 55), quando afirma que não se pode negar a "necessidade de uma formação técnica do trabalhador, [o que não significa a formação que resulta] num especialista estreito e alienante". Na percepção de Araújo (2012, p. 255), os saberes de experiências dos camponeses:

[...] por si só são insuficientes para dar conta, na atualidade, da complexidade a que estão submetidos nas relações socioeconômicas no campo. Nesse contexto, percebe-se que os mesmos trabalhadores, que foram alijados do acesso à escola, também foram alijados de uma formação profissional consistente e coerente com as suas demandas (ARAÚJ 0, 2012, p. 255).

Essa compreensão nos remete à ideia de que a profissionalização da classe trabalhadora do campo deve ter como uma de suas referências os parâmetros políticopedagógicos da Educação do Campo, uma vez que não se trata de pensar a educação profissional específica para o campo em separado do debate, em geral, das concepções de políticas públicas de educação profissional. Para Caldart (2010) faz-se necessário trazer para o debate: 
[...] questões que têm sido formuladas desde a realidade, esta, sim, específica, do trabalho no campo, dos embates de projetos de desenvolvimento, de modos de fazer agricultura e das experiências de formação profissional dos sujeitos, [o que] inclui a preparação das diferentes profissões que são necessárias ao desenvolvimento do território cuja base [...] está na agricultura: agroindústria, gestão, educação, saúde, comunicação, mas sem desconsiderar que a produção agrícola é a base da reprodução da vida e, por isso, deve ter centralidade na formação para o trabalho do campo (CALDART, 2010, p. 230 e 236).

Neste sentido, a qualificação social e profissional há de ser pensada a partir das mudanças no mundo do trabalho, que hoje também estão presentes no campo, assim como as tecnologias, o que levanta questões sobre como o campo pode produzir, a partir dos saberes de experiência, outras formas de utilização da técnica em favor da vida.

Atento a essas mudanças, o PJC-ST assumiu a agroecologia como base técnica comum da QSP e como estratégia de integração, tendo o trabalho como princípio educativo. Essa ideia é corroborada por Ramos (2006), quando nos alerta para o sentido histórico do trabalho no sistema capitalista que, ao se transformar em trabalho assalariado “[...] traz fundamentos que orientam finalidades da formação, na medida em que expressa as exigências específicas para o processo educativo, visando à participação direta dos membros da sociedade no trabalho socialmente produtivo" (RAMOS, 2006, p. 78).

Seguindo essa direção de análise, torna-se necessário relacionar o âmbito escolar à prática social concreta, pois trata-se de considerar o imbricamento entre cultura $e$ formação, na perspectiva de repensar a ciência como produção de conhecimentos "legitimados socialmente ao longo da história [...] na busca da compreensão e transformação dos fenômenos naturais e sociais" (RAMOS, 2006, p. 79). Nesta perspectiva, para a autora, a formação profissional "[...] é um meio pelo qual o conhecimento científico adquire, para o trabalhador, o sentido da força produtiva, traduzindo-se em técnicas e procedimentos, [que envolvem] conceitos científicos e tecnológicos básicos" (RAMOS, 2006, p. 79).

Com esta ênfase, o PJC-ST tem, na concepção de currículo integrado, a compreensão do processo que articula os saberes científicos e os saberes populares, apropriando-se dos eixos da ciência, da cultura, do trabalho e da tecnologia. Num movimento de mão dupla, trabalha-se com a ciência e com os conhecimentos oriundos das vivências laborais, objetivando-se como síntese a produção de novos saberes na perspectiva da transformação da realidade. Para tanto, vai além da tradicional organização do trabalho pedagógico.

A concretização desse currículo requer elementos metodológicos que se baseiam na concepção de escola como formadora de sujeitos, articulada a um projeto de emancipação humana que valoriza os diferentes saberes no processo educativo. A proposta do percurso formativo do PJC-ST reconhece o homem como sujeito do conhecimento, esse produzido na interação com o mundo social e tomado como instrumento de transformação da realidade, do mundo (TSE-TUNG, 2009). O conhecimento produzido na interação com o mundo social possibilita assim desvelar a aparência, com vistas à apreensão da essência - orientadora de caminhos a trilhar - toma 
da como conteúdo da compreensão e transformação da realidade. Para tanto, a proposta envolveu elementos metodológicos estruturantes em diferentes tempos formativos da alternância pedagógica, quer sejam, Tempo Escola (TE) e Tempo Comunidade (TC), compreendidos como tempos contínuos do processo educativo, onde se buscou articular teoria e prática, tendo como ponto de partida a pesquisa sobre a dinâmica sociocultural e o processo produtivo em que estão envolvidos os sujeitos.

Nessa práxis, o percurso formativo do PJC-ST esteve constantemente marcado pelas reconstruções de diferentes saberes, fazeres e concepções, na perspectiva da educação libertadora e da transformação das realidades das comunidades envolvidas.

\section{OTRABALHO COMO PRINCÍPIO EDUCATIVO:TECNOLOGIA E SABERES POPULARES}

No Brasil, o trabalho enquanto princípio educativo vem sendo assumido como base da proposta pedagógica de alguns movimentos sociais camponeses, desde a década de 1980, em especial nas discussões do Movimento dos Trabalhadores Rurais Sem Terra (MST). No caso específico do PJ C-ST, destacamos o protagonismo dos movimentos sociais do campo na base de sua formulação e experimentação, cujas experiências foram incorporadas aos princípios político-pedagógicos, que sustentam o Programa, conforme Projeto Político Pedagógico:

[...] todo conhecimento seja ele científico ou da prática social, é dado pela ação dos seres humanos sobre a natureza e da sociedade pelo trabalho. Portanto o eixo de todo o conhecimento é o trabalho humano. 0 trabalho como princípio educativo orienta o desenvolvimento do Programa, de modo a resgatar os valores do trabalho coletivo e contribuir para a autonomia e 0 empoderamento dos jovens agricultores familiares (BRASIL, 2008a, p. 47).

Assim, no PJC-ST, reafirma-se o trabalho como princípio educativo do processo pedagógico, a partir do qual se fortaleceram metodologias que permitiram o estudo, a pesquisa e a experimentação com a realidade como práticas mobilizadoras do processo de formação. Nessa dinâmica, a agroecologia ganhou sentido estratégico, pois não se configurou apenas como um "corpo de conhecimentos úteis [mas] como prática social" (GUHUR; TONÁ, 2012, p. 62). Uma tecnologia que tem sido colocada como parte da "estratégia de luta e de enfrentamento ao agronegócio e ao sistema capitalista de exploração dos trabalhadores e de depredação da natureza" (GUHUR; TONÁ, 2012, p. 62). Nessa perspectiva, o trabalho com:

[...]a agroecologia exige que o camponês passe a assumir uma posição ativa, de pesquisador das especificidades de seu agroecossistema, para desenvolver tecnologias apropriadas não só às condições locais de solo, relevo, clima e vegetação, mas também às interações ecológicas, sociais, econômicas e culturais (GUHUR; TONÁ, 2012, p. 62).

Ainda dialogando com esses autores, apesar do termo agroecologia ter se popularizado nos anos 1980, foi somente a partir de 1989, com a publicação do livro "Agroecologia: as bases científicas da agricultura alternativa", de Miguel Altieri, que come 
çou a ser utilizado no Brasil. Os movimentos sociais populares do campo, em especial aqueles vinculados à Via Campesina ${ }^{5}$, incorporaram 0 debate agroecológico à sua estratégia política, no final da década de 1990, e, com maior força, a partir do início dos anos 2000, passaram a contribuir ampliando sua concepção.

Na perspectiva do trabalho e da pesquisa como princípios educativos, no PJC-ST os saberes populares oriundos das práticas de cultivo dos camponeses são chamados a dialogar com o conhecimento tecnológico produzido, promovendo assim a ampliação das leituras de mundo e possíveis mudanças no seu quefazer nas práticas agrícolas convencionais. Nesse sentido, a ênfase do movimento de formação de educandos e educadores, em meio às suas contradições, buscou pautar uma compreensão da agroecologia como:

[...] inseparável da luta pela soberania alimentar e energética, pela defesa e recuperação de territórios, pelas reformas agrária e urbana, e pela cooperação e aliança entre os povos do campo e da cidade. A agroecologia se insere dessa maneira, na busca por construir uma sociedade de produtores livremente associados para a sustentação de toda a vida (VIA CAMPESINA; MST, 2006 apud GUHUR; TONÁ, 2012, p. 59).

Na experiência do PJC-ST, em diferentes momentos do percurso formativo foram confrontados os modelos de agricultura. Os educadores que atuavam juntos em cada turma, ou seja, os 4 educadores vinculados às áreas de conhecimento, envolveram-se durante 0 desenvolvimento dos Eixos Temáticos ${ }^{6}$, no processo formativo com a apropriação dos conceitos que tencionam o campo. No fazer de alguns desses educadores, encontramos a afirmação desta disputa, o que dá margem para problematizar a falta de acesso dos camponeses à terra.

[...] ao discutirmos os processos da produção agroecológica e suas potencialidades, necessariamente discute-se a questão agrária e o problema da falta de acesso dos trabalhadores camponeses à terra. Assim, as técnicas agroecológicas contrapõem um modelo de agricultura convencional, atualmente intitulado de Agronegócio, baseado no lucro e na concentração de terras, ou mesmo no fetiche da modernização agrícola das pequenas propriedades (ROSA et al., 2012, p. 347).

A agroecologia como tecnologia alternativa de cultivo também pode ser confrontada considerando o vínculo do trabalho informal dos educandos, onde eram obrigados pelos patrões a utilizarem veneno nas lavouras. Ou seja, a tecnologia utilizada na degradação do trabalho e da dignidade da vida no campo, passa a ser tomada como conteúdo que permite problematizar as práticas de cultivo da agricultura convencional e explorar outras com base tecnológica construída a partir de saberes populares, no cultivo das lavouras e no tratamento das pragas, como alternativa ao manejo do veneno, que compromete a vida como um todo. A condição desumana de trabalho a que estavam submetidos os educandos levou os educadores a explorar com eles outras formas de produzir agricultura, como se pode observar no relato de um dos educadores: 


\begin{abstract}
Tentamos começar a ensiná-los a produzir produtos orgânicos para o seu próprio consumo eem menor escala, mas eles tinham em mente que esses tipos de produtos demoravam muito para se desenvolver e que muitas vezes as pragas e as doenças interrompiam esse processo, trazendo sérios prejuízos a sua lavoura. [...] Ciências Agrárias trabalham com o preparo de biofertilizantes e defensivos alternativos para as pragas e doenças [contribuindo] para o crescimento das plantas. Hoje, os nossos educandos estão com um "novo olhar" sobre a agricultura orgânica. Toda a produção voltada para o consumo próprio passou a ser orgânica. Com o começo dos estudos do eixo 4 "Economia Solidária" os nossos educandos começaram a demonstrar interesse em estar comercializando os poucos produtos que já estão sendo produzidos em suas propriedades (SANTANA et al., 2012, p. 585-586).
\end{abstract}

Por meio dos planos de pesquisa, o trabalho coletivo foi fortalecido, as ideias de cooperativismo afloraram nas comunidades e outros projetos foram incentivados, dentre eles a organização por meio de associação para fornecimento de produtos da agricultura familiar para o Programa de Aquisição de Alimentos (PAA). Algumas turmas tiveram apoio dos movimentos sociais do campo, especialmente do MPA, e intensificaram os espaços de trabalho coletivo no cultivo de hortas, nos mutirões para a colheita do café, abrindo espaços para as visitas técnicas, fortalecendo com isso a QSP.

Essas práticas levadas a efeito, junto às comunidades envolvidas, reafirmam a premissa da educação popular como prática educativa que envolve múltiplos espaços "coletivos e organização de base, movimentos sociais, organizações civis, experiências escolares e culturais etc. [que buscam] contribuir para a constituição de diversos setores subalternos como sujeitos de transformação" (CARRILO, 2013 apud TORRES, 1993, p. 19). O exercício da construção social coletiva exercitado entre as diversas equipes, possibilitou reflexões sobre as reais necessidades de formação profissional dos camponeses, considerando a diversificação de suas atividades laborais, para além da atividade agrícola.

Nas propriedades, as atividades são desenvolvidas pela família de forma coletiva, divididas em tarefas, troca de dias, individual, etc. Mas também existem outras profissões que são desenvolvidas no assentamento, como: professor, técnico agrícola, pedreiro, agente de saúde, enfermeiro, tratorista, etc. Isso demonstra uma diversidade de funções e atividades desenvolvidas no campo e no assentamento que não estão relacionadas diretamente à agricultura, mas que são necessárias para a vida das pessoas das comunidades do campo (ARANTES et al., 2012, p. 419).

Essa percepção nos leva a retomar o alerta de Caldart (2010) em relação à formação profissional para o trabalho no campo, o que se constituía realidade frente aos modelos de desenvolvimento e modos de fazer agricultura em disputa, e o que se demanda de formação profissional, nas diferentes áreas, sem perder de vista a produção de base agrícola.

QUALIFICAÇÃO SOCIAL E PROFISSIONAL COMO ELEMENTOS DA INTEGRAÇÃO CURRICULAR A PARTIR DOS PRINCÍPIOS DA EDUCAÇÃO POPULAR

Voltamo-nos neste item a explorar os principais aspectos da experiência vivida por educadores e educandos referentes à escolarização na etapa de ensino fundamental 
aliada à qualificação social e profissional. Importa considerar que esta não foi uma tarefa fácil, uma vez que envolveu lidar com as contradições que emergiram no processo, a desarticulação da equipe formadora no âmbito da qualificação profissional aliada à garantia de estrutura e equipamentos públicos para tal fim.

Ao tematizarmos a QSP na perspectiva dos movimentos sociais, ressaltamos a compreensão de sua complexidade, que se evidencia no caráter ambíguo e contraditório da ação desses movimentos, ora voltada para a transformação social, ora para a manutenção da ordem vigente (AGUIAR; BOLLMANN, 2011). No caso específico da experiência do PJC-ST, isso se evidenciou na ação concreta de instâncias identificadas no processo, como parceiras, como a do Sindicato Patronal Municipal, que mantém vinculações com o Serviço Nacional de Aprendizagem Rural (SENAR). Como sabemos, o SENAR representa um dos setores mais conservadores do agronegócio, que é a Confederação Nacional da Agricultura (CNA). Essa parceria constituiu-se, a nosso ver, uma atuação marcadamente contraditória à perspectiva dos princípios da Educação do Campo, uma vez que se volta para uma formação pontual, orientada por uma lógica privatista para atender ao mercado de trabalho e responder aos interesses do agronegócio e tornar o trabalhador do campo meramente técnico, preparando-o somente para atuar na condição de empregado.

A ausência do Estado no cumprimento do seu dever de institucionalizar as parcerias para prover condições de efetivação da proposta evidenciou-se, assim, numa das contradições do percurso do Programa. Para a equipe de formação, essas parcerias firmadas pelos educadores, com diferentes entidades e órgãos públicos, precisavam ter sido avaliadas.

Contudo algumas equipes, que se articularam com o Sindicato Patronal do Município para conseguir os cursos do SENAR, refletem sobre essa contradição e justificam como sendo a única opção de oferta gratuita encontrada, assumindo o desconhecimento de outras opções. Conforme relatam: "[...] na ocasião da busca de parcerias, a instituição encontrada foi apenas o Sindicato Patronal de Nova Venécia, que realizava ações profissionais através da parceria com o SENAR" (CARDOSO et al., 2012, p. 291).

As parcerias buscadas por outras equipes com o Movimento de Pequenos Agricultores (MPA) e o Sindicato dos Trabalhadores Rurais (STR) fizeram a contraposição à proposta de formação para o mercado de trabalho. Nessas parcerias, a ideia da coletividade foi trabalhada, no sentido de fortalecer a organização de grupos, da classe trabalhadora do campo e a importância da participação nos movimentos sociais, "[...] levando os educandos a perceberem que as conquistas em grupo são mais acessíveis que individualmente" (PARTELLI et al., 2012, p. 318).

É importante ressaltar que, embora a proposta de QSP do Programa tenha sido formulada a partir da experiência inicial vivida pelos movimentos sociais do campo, no contexto do PJC-ST no ES, a indução da política revelou suas contradições ao nos depararmos com os reais sujeitos destinatários, em que cerca de $40 \%$ das turmas eram compostas por assalariados rurais que viviam no campo, mas que nem todos tiravam da terra seu sustento, tendo que vender sua força de trabalho nas fazendas (migrantes sazo 
nais) e até mesmo nas cidades. Isto também foi visto pelos educadores como um dos aspectos contraditórios do Programa (CARDOSO et al., 2012).

Assim, atender a essa demanda de escolarização se constituiu um desafio principalmente para o exercício da Pedagogia da Alternância que precisou ser ressignificada para atender à especificidade da EJA e as condições de trabalho dos educandos, como já salientado anteriormente. Embora em muitos aspectos contraditórios com a proposta inicial da QSP, "o processo de discussão e escolha das ações de qualificação profissional foi pedagogicamente produtivo e construtivo, pois gerou discussões e reflexões quanto à constituição desses sujeitos" (CARDOSO et al., 2012, p. 291-292). A integração e o diálogo entre os saberes como princípios do Programa tornaram-se um desafio que exigia a abertura de todos os envolvidos, num exercício de desconstrução da lógica compartimentalizada do conhecimento, dissociado da realidade social e histórica. Nesse sentido, Ramos (2005) traz para pensar o currículo integrado como aquele que tem como base a compreensão do real como totalidade histórica e dialética.

As práticas relacionadas à QSP, desenvolvidas na alternância pedagógica, permitiram compreender a visão dos educandos sobre o jeito de ensinar no PJC-ST, pois eles valorizavam a oportunidade de receber os professores em suas casas e na plantação. Para eles, essa aproximação com suas atividades laborais se refletia na sua autoestima e nas suas práticas produtivas, especialmente na tomada de consciência em relação aos perigos do uso de agrotóxicos nas lavouras e a consequente ação de aprender e disseminar as práticas da ag roecologia.

As atividades de integração projetadas a partir dos pontos de aprofundamento indicados nos Círculos de Diálogo ${ }^{7}$ e desenvolvidas dentro dos eixos temáticos, apontam para a realidade concreta tematizada, que passou a constituir-se como campo de estudo, de ciência (RAMOS, 2010). Conforme relatam os educadores, a problematização da realidade proporciona ao educando "[...] perceber-se como sujeito atuante na história e no ambiente em que vive, podendo ajudar a tomar decisões e buscar melhorias para a sua comunidade" (ARAUJO et al., 2012c, p. 494-495).

Ao eleger a agroecologia como base tecnológica, abriu-se espaço para a experimentação nas práticas de produção da Horticultura e da Agroindústria, ao mesmo tempo em que provocou o combate ao agrotóxico, uma das principais temáticas exploradas, no âmbito da formação profissional, conforme relatado pelo educador:

\begin{abstract}
Acreditamos que, ao trabalharmos uma oficina de caldas naturais, estamos desenvolvendo uma série de conteúdos que contribuem para a formação social, profissional e acadêmica do educando. Descobrir formas de utilizar inseticidas naturais para o controle de pragas, avaliar as consequências causadas pelo agrotóxico no meio ambiente, compreender o controle biológico existente nas plantações, aprender técnicas de controle alternativo que garantem a sustentabilidade nas propriedades, além de estar treinando a escrita e a leitura na elaboração de cartilhas e relatórios (MENEGUSSI et al., 2012, p. 186).
\end{abstract}

O acompanhamento das turmas e os relatos dos educadores nos deram elementos para pensar a formação dos trabalhadores "como dirigentes, tendo como horizonte a superação da dominação dos trabalhadores e perspectivas de emancipação" 
(RAMOS, 2010, p.52), cuja materialidade encontramos no relato acerca da experiência das visitas técnicas:

Na visita à carvoeira, observamos a degradação ambiental e humana, exploração da força de trabalho sem remuneração digna, ultrapassando a jornada de trabalho, enquanto que o lucro gerado pelo trabalhador se concentra nas mãos do dono da empresa. [...] no lote do Assentamento Celestina, [...] a relação de trabalho está ligada a sustentabilidade das famílias, o trabalho desenvolvido é familiar, a produção é para consumo e o excedente é entregue às escolas, periferias, asilos, através do Programa de Aquisição de Alimentos. Observa-se que a relação com o meio é de preservação e não de degradação (MENEGUSSI et al., 2012, p. 181-182).

Tal prática coloca em debate diferentes maneiras de se relacionar com a terra, 0 que fertiliza a compreensão não somente acerca da degradação ambiental, como também sobre o trabalho na lógica do capital, o que possibilita a compreensão dos sentidos da integração apontados por Ramos (2010, p. 54), mais especificamente ao que se refere à formação humana omnilateral, que se configura num "processo educacional que integra, de forma unitária, as dimensões fundamentais da vida - trabalho, conhecimento (ciência e tecnologia) e cultura -, tendo o trabalho, nos sentidos ontológico e histórico, como princípio educativo" (RAMOS, 2010, p. 54).

Possibilita-nos ainda refletir sobre o diálogo dos diferentes saberes e de como foi possível integrá-los nos diferentes tempos e espaços de aprendizagem, respeitando o modo de viver dos camponeses e suas formas de produzir sua existência. Conforme relato dos educadores,

A integração dos saberes científicos com os saberes locais acontece a partir do conhecimento que cada educando tem desde suas práticas diárias e também a partir dos conhecimentos herdados dos seus antepassados [...] como formas de plantio, maneiras de fazer a poda de algumas plantas, uso de plantas medicinais e até mesmo na culinária. Procuramos integrar esses conhecimentos empíricos aos saberes científicos, construindo assim um novo conhecimento integrado.[...] Os conhecimentos se integram quando se desenvolve o plano de pesquisa, pois, neste momento, os educandos começam a elencar algumas dúvidas sobre o tema estudado e sobre o que já existe em seu conhecimento acumulado.[...] 0 aprofundamento dos conteúdos científicos se dá através do diagnóstico da pesquisa, no qual se comprova uma determinada situação problema, cabe ao saber científico buscar elementos de estudo sobre o mesmo. Como exemplo, podemos citar o processo de adubação química, não sabendo dos recursos naturais que perdiam nas propriedades e que poderiam ser reaproveitados em forma de compostagem melhorando não só o estado nutricional das plantas, mas também toda a vida existente no solo, retomando a relação homem natureza. (MENEGUSSI et al., 2012, p. 183-185).

A compreensão desses educadores acerca da integração e diálogo entre os saberes dialoga com as reflexões de Ramos (2010) acerca dos pressupostos filosóficos que fundamentam a organização curricular na perspectiva do currículo integrado, e apontam para a concepção de homem como ser histórico-social, 
[...] que age sobre a natureza para satisfazer suas necessidades e, nessa ação, produz conhecimentos como síntese da transformação da natureza e de si próprio. Assim, a história da humanidade é a história da existência humana, e a história do conhecimento é a história do processo de apropriação social dos potenciais da natureza pelo o próprio homem, mediada pelo trabalho (RAMOS, 2010, p. 114).

Contudo, a pesquisa nos mostra que nem todas as equipes compreenderam a proposta de currículo integrado. Conforme alguns relatos, trata-se de um tema que demanda muito estudo e persistência e o exercício do trabalho coletivo na perspectiva da promoção do diálogo entre os saberes, conforme aprendemos com Paulo Freire. "O diálogo, como encontro dos homens para a tarefa comum de saber agir, se rompe, se seus polos (ou um deles) perde a humildade" (FREIRE, 1975, p. 95).

\section{O LEGADO DO PROJ OVEM CAMPO - SABERES DA TERRA NO ES}

A sistematização buscada no movimento da pesquisa nos permite reunir algumas reflexões sobre o percurso e as vivências compartilhadas. No contexto de políticas neoliberais que imperam na conjuntura educacional no ES, a proposta do PJC-ST afirma seu caráter contra-hegemônico em relação ao que tem se configurado como política assumida pelo Estado, no sentido de garantir o direito à educação e, principalmente, a oferta da formação dos trabalhadores camponeses. Neste sentido, a busca de sua continuidade foi pautada junto à Secretaria de Estado como uma reivindicação de todos os envolvidos, o que significaria tomar a proposta como referência de política pública estruturante para a formação profissional de jovens e adultos camponeses.

Como legado, vários dados levantados revelam pontos positivos e enraizamentos produzidos nas comunidades a partir das ações do Programa. Do ponto de vista da qualificação social, muitos dos educandos se inseriram em movimentos sociais entre outras organizações nas suas comunidades. Quanto ao trabalho com a qualificação profissional, não podemos deixar de destacar a apropriação dos princípios da agroecologia, que passaram a ser exercitados, seja nas propriedades, na escola ou em terrenos cedidos pelas comunidades para a realização da formação profissional, consequentemente evidenciando resultados concretos no fazer da agricultura com base na tecnologia agroecológica.

Em meio às contradições evidenciadas, tendo em vista o objetivo do Programa, podemos depreender que o currículo integrado, com base nos eixos trabalho, ciência, cultura e tecnologia, pôde ser vivenciado a partir da prática de integração do TE e TC. Os projetos ligados às práticas da QSP tiveram papel importante na integração das áreas e em muito contribuíram para mudanças no cenário local, por meio de oficinas promovidas pelos educadores, como a que citamos como exemplo, voltada à produção de inseticidas naturais.

A potencialidade das práticas desenvolvidas no percurso do PJC-ST aponta para um projeto de formação da classe trabalhadora do campo na perspectiva de sua emancipação, onde o diálogo dos saberes é considerado fundamental para romper com o silêncio e promover a reflexão e a problematização da realidade. Neste sentido, a alternância pedagógica se constituiu ferramenta metodológica fundamental e fortaleceu 
a ideia de que as dificuldades e desafios quando enfrentados coletivamente se constituem em possibilidades.

Tal experiência reafirma a importância da formação, por meio do currículo integrado na EJA com qualificação social e profissional, e fortalece a luta para que a proposta de escolarização dos camponeses, na perspectiva da educação popular e da Educação do Campo, respeite seus tempos e espaços de formação, como política pública. Como se trata de uma colheita orgânica, coloca-se como aposta que as sementes plantadas nessa experiência gerarão novos frutos. Este é o legado da utopia que tem que ser construído coletivamente.

Artigo recebido em: 03/12/2018

Aprovado para publicação em: 30/01/2019

\section{SOCIAL AND PROFESSIONAL QUALIFICATION FROM THE LOGIC OF THE FIELD SOCIAL MOVEMENTS}

ABSTRACT: This article addresses the results of a master's research conducted during the implementation of the Program "ProJovem Campo Saberes da Terra (PJC-ST)" in the state of ES, aimed at the schooling of peasants, with Social and Professional Qualification (QSP) in the Adult and Youth Education (EJA) modality. It aims to make explicit the challenges posed to the professional development process in the countryside, in the practices of Professional Education. The theoretical background is based on the contributions of popular education, the fundamentals and principles of agroecology and the work as an educational principle for the exercise of curricular integration. The methodology of systematization is assumed as a way of revisiting the practice and analyzing it critically. The results indicate contributions to EJA's public policy, having the dialogue of knowledge, pedagogic alternation and QSP practices as integrating elements of the curriculum.

KEYWORDS: Social Movements. Social and Professional Qualification. Youth and Adult Education. Countryside Education.

\section{QUALIFICACIÓN SOCIAL Y PROFESIONAL A PARTIR DE LA LÓGICA DE LOS MOVIMIENTOS SOCIALES DEL CAMPO}

RESUMEN: El texto aborda resultados de la investigación de maestría realizada a partir de la implementación del Programa ProJ ovem Campo - Saberes de la Tierra (PJC-ST) en el estado de ES, enfocado en la escolarización de campesinos con Calificación Social y Profesional (QSP) en la modalidad Educación de Jóvenes y Adultos-EJA. Tiene como objetivo explicitar los desafíos planteados a los procesos formativos en el contexto del campo, en las prácticas de Educación Profesional. Toma como aportes teóricos la educación popular, los fundamentos y principios de la agroecología y el trabajo como principio educativo para el ejercicio de la integración curricular. La metodología de la sistematización es asumida como forma de revisar la práctica y analizarla críticamente. Los resultados indican contribuciones al campo de la política pública de la modalidad de EJ A, teniendo el diálogo de los saberes, la alternancia pedagógica y las prácticas de QSP como elementos integradores del currículo. 
OLIVEIRA, E. C.; FERREIRA, M. G. M.

PALABRAS CLAVE: Movimientos Sociales. Calificación social y profesional. Educación de Jóvenes y Adultos. Educación del Campo.

\section{NOTAS}

1) O termo foi criado para expressar as relações econômicas (mercantis, financeiras e tecnológicas) entre setor agropecuário e aqueles situados na esfera industrial (tanto de produtos destinados à agricultura, quanto de processamento daqueles com origem no setor), comercial e de serviços (LEITE; MEDEIROS, 2012, p. 79).

2) "Trata-se de uma nova abordagem que integra os princípios agronômicos, ecológicos e socioeconômicos à compreensão e avaliação do efeito das tecnologias sobre os sistemas agrícolas e a sociedade como um todo. Ela utiliza os agroecossistemas como unidade de estudo, ultrapassando a visão unidimensional - genética, agronômica, edafológica - incluindo dimensões ecológicas, sociais e culturais" (ALTIERI, 2004, p. 23).

3) Arco ocupacional é o conjunto de ocupações que possuem base técnica comum, neste caso a agroecologia. 0 arco Produção Rural Familiar é composto por 5 ocupações: Sistemas de Cultivo, Sistemas de Criação, Extrativismo, Associativismo e Aquicultura, de acordo com a Resolução no 4/1999 do CNE (BRASIL, 2008a).

4) "Entendida como uma metodologia que combina períodos integrados de formação na escola e formação na família/comunidade, possibilitando, dessa forma, a flexibilização da organização do trabalho pedagógico em alternâncias e adequando-o à realidade dos sujeitos educativos" (BRASIL, 2008b, p. 22).

5) De acordo com Fernandes (2012), a Via Campesina tornou-se a mais ampla e mais conhecida articulação mundial de organizações na luta pelo desenvolvimento da agricultura camponesa, na perspectiva da soberania alimentar, com base no desenvolvimento local e na diversidade da produção agrícola e agroecológica, defesa das terras e territórios camponeses e indígenas e defesa das sementes como patrimônio da humanidade e da água como direito de todos.

6) Fundamentam a organização curricular que está organizada no eixo articulador Agricultura Familiar e Sustentabilidade e nos eixos temáticos: Agricultura Familiar; Identidade; Gênero; Etnia; Desenvolvimento Sustentável e Solidário com Enfoque Territorial; Sistemas de Produção e Processos de Trabalho no Campo; Economia Solidária e Cidadania; Organização Social e Políticas Públicas. Agregam conhecimentos da formação profissional e das áreas de conhecimento para elevação da escolaridade (BRASIL, 2008a).

7) No PJC-ST, constituiu-se em um dos componentes formativos, referindo-se à atividade desenvolvida no Tempo Escola (BRASIL, 2008).

\section{REFERÊNCIAS}

AGUIAR, L. C.; BOLLMANN, M. da G. N. M ovimentos sociais em educação e suas contribuições à política educacional brasileira. In: TEODORO, A.; J EZINE, E. (Org.). Movimentos sociais e educação de adultos na Ibero-América: lutas e desafios. Brasília: Liber Livro, 2011. 
ALTIERI, M. Agroecologia:a dinâmica produtiva da agricultura sustentável. Porto Alegre: Editora da UFRGS, 2004.

Agroecologia: bases científicas para uma agricultura sustentável. São Paulo, Rio de Janeiro: Expressão Popular, 2012.

ARANTES, B. et al. Relato de experiências e reflexões - Equipe Castro Alves. In: SCARIM, P. C.; OLIVEIRA, E. C. de (Org.). Experiências que brotam da terra: as reflexões e vivências dos educadores e educadoras. Coleção ProJ ovem Campo Saberes da Terra Capixaba. Vitória: GM Editora, 2012, p. 411-436.

ARAÚJO, M. N. Educação de Jovens e Adultos (EJA). In: CALDART, R. S. et al. Dicionário da Educação do Campo. Rio de J aneiro, São Paulo: Escola Politécnica de Saúde J oaquim Venâncio, Expressão Popular, 2012.

BOTTOMORE, T. Dicionário do Pensamento Marxista. Rio de J aneiro: J orge Zahar Editor, 1988.

BRASIL. Ministério da Educação. Projeto Político Pedagógico - ProJ ovem Campo - Saberes da Terra. Secretaria de Educação Continuada, Alfabetização e Diversidade. Coleção Cadernos Pedagógicos do ProJ ovem Campo - Saberes da Terra. Brasília: MEC/SECAD, 2008a.

BRASIL. Ministério da Educação. Percurso Formativo - ProJ ovem Campo - Saberes da Terra. Secretaria de Educação Continuada, Alfabetização e Diversidade. Coleção Cadernos Pedagógicos do ProJ ovem Campo - Saberes da Terra. Brasília: MEC/SECAD, 2008b.

CALDART, R. S. (Org.). Caminhos para transformação da escola: reflexões desde práticas da licenciatura em educação do campo. São Paulo: Expressão Popular, 2010.

CARRILO, A. T. A educação popular como prática política e pedagógica emancipadora. In: STRECK, D. R.; ESTEBAN, M. T. (Org.). Educação popular:lugar de construção coletiva. Petrópolis: Vozes, 2013.

FERNANDES, B. M. Territórios da Educação do Campo. In :CALDART, R. S. et al. Dicionário da Educação do Campo. Rio de J aneiro, São Paulo: Escola Politécnica de Saúde J oaquim Venâncio, Expressão Popular, 2012.

FREIRE, P. Pedagogia do oprimido. Rio de J aneiro: Paz e Terra, 1975.

. Educação e Mudança. Rio de Janeiro: Paz e Terra, 1983.

. Pedagogia da autonomia: saberes necessários à prática educativa. São Paulo: Paz e Terra, 2001. Coleção Leitura.

. A importância do ato de ler: em três artigos que se completam. São Paulo: Cortez, 2011.

GUHUR, D. M. P.; TONÁ, N. Agroecologia. In: CALDART, R. S. et al. Dicionário da Educação do Campo. Rio de Janeiro, São Paulo: Escola Politécnica de Saúde Joaquim Venâncio, Expressão Popular, 2012. 
OLIVEIRA, E. C.; FERREIRA, M. G. M.

KONDER, L. O futuro da filosofia da práxis: o Pensamento de Marx no século XXI. São Paulo: Paz e Terra, 1992.

LEITE, S. P.; MEDEIROS, L. S. de. Agronegócio. In: CALDART, R. S. et al. Dicionário da Educação do Campo. Rio de Janeiro, São Paulo: Escola Politécnica de Saúde Joaquim Venâncio, Expressão Popular, 2012.

MENEGUSSI, F. et al. Relato de experiências e reflexões - Equipe Praça Rica. In: SCARIM, P. C.; OLIVEIRA, E. C. de (Org.). Experiências que brotam da terra: as reflexões e vivências dos educadores e educadoras. Coleção ProJ ovem Campo Saberes da Terra Capixaba. Vitória: GM Editora, 2012, p. 173-194.

MOLINA, M. C. Análises de práticas contra-hegemônicas na formação de educadores: reflexões a partir do curso de licenciatura em Educação do Campo. In: CUNHA, C. da et al. O método dialético na pesquisa em educação. Campinas: Autores Associados/ Brasília, DF: Faculdade de Educação, Universidade de Brasília, UnB, 2014.

PARTELLI, C. M. et al. Relato de experiências e reflexões - Equipe Valério. In: SCARIM, P. C.; OLIVEIRA, E. C. de (Org.). Experiências que brotam da terra: as reflexões e vivências dos educadores e educadoras. Coleção ProJ ovem Campo Saberes da Terra Capixaba. Vitória: GM Editora, 2012, p. 295-324.

RAMOS, M. N. Possibilidades e desafios na organização do currículo integrado. In: FRIGOTTO, G. et al (Org.). Ensino médio integrado: concepções e contradições. São Paulo: Cortez, 2005.

RAMOS, M. N. Currículo integrado. In: Escola Politécnica de Saúde Joaquim Venâncio e Estação de Trabalho Observatório de Técnicos em Saúde (Org.). Dicionário da educação integral em saúde. Rio de J aneiro: EPSJ V, 2006.

. Ensino médio integrado: ciência, trabalho e cultura na relação entre educação profissional e educação básica. In: (Org.) Educação profissional e tecnológica no Brasil contemporâneo: desafios e possibilidades. Porto Alegre: Artmed, 2010.

ROSA, J F. B. et al. Relato de experiências e reflexões - Comunidade Córrego Farias. In: SCARIM, P. C.; OLIVEIRA, E. C. de (Org.). Experiências que brotam da terra: as reflexões e vivências dos educadores e educadoras. Coleção ProJ ovem Campo Saberes da Terra Capixaba. Vitória: GM Editora, 2012, p. 327-357.

SANTANA, C. et al. Relato de experiências e reflexões - Turma Piracema. In: SCARIM, P. C.; OLIVEIRA, E. C. de (Org.). Experiências que brotam da terra: as reflexões e vivências dos educadores e educadoras. Coleção ProJ ovem Campo Saberes da Terra Capixaba. Vitória: GM Editora, 2012, p. 571-591.

TSE-TUNG, M. Sobre a prática - sobre a contradição. São Paulo: Expressão Popular, 2009. 
Edna Castro de Oliveira: Doutora em Educação Brasileira pela Universidade Federal Fluminense (UFF), Mestre em Educação pela Universidade Federal do Espírito Santo (UFES), graduada em Pedagogia pela UFES. Atualmente é professora Associada da UFES, integra a Linha de Pesquisa" Educação, Formação Humana e Políiticas Públicas do PPGE/CE/UFES. Coordenadora do Núcleo de Educação de Jovens e Adultos. Tem se dedicado a estudos que envolvem as políticas e práticas de EJA integrada à educação profissional, de alfabetização e de formação de educadores e educação do campo, em interlocução com os movimentos sociais.

E-mail: oliveiraedna@yahoo.com.br

Maria Geovana Melim Ferreira: Graduada em Pedagogia e Mestre em Educação pela Universidade Federal do Espírito Santo; Pedagoga da Rede Estadual de Ensino do Espírito Santo; Membro do Fórum EJA-ES, do Fórum Nacional de Educação do Campo e do Comitê de Educação do Campo do Espírito Santo.

E-mail: mariageovana.mf@gmail.com

Este periódico utiliza a licença Creative Commons Attribution 3.0, para periódicos de acesso aberto (Open Archives Iniciative - OAI). 